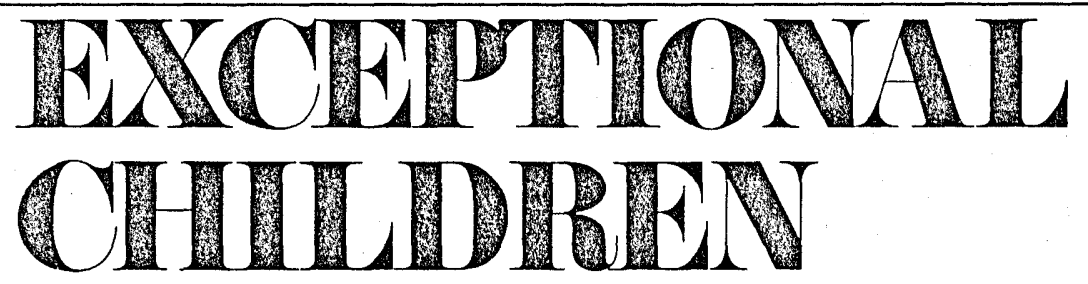

\title{
A PROPOSED MODEL FOR SELECTING, MODIFYING, OR DEVELOPING INSTRUCTIONAL MATERIALS FOR HANDICAPPED CHILDREN
}

\section{LEARNING DISABILITIES AND INSTRUCTIONAL MATERIALS}

\section{By E. Eugene Ensminger ${ }^{1}$}

Although the decade of the sixties was marked with many significant achievements in the education of handicapped children, two of these achievements in particular will rank near the top of any listing of outstanding accomplishments. One of them was the heavy emphasis upon the development of instructional materials for the handicapped. The other was the renewed effort to develop diagnostic assessment devices with the purpose of prescribing appropriate educational experiences for the child.

Both of these movements have had a common educational objective, i.e. to provide the child who has a specific learning problem an appropriate and successful learning experience. However, a common rationale has not guided the development of diagnostic devices and the development of instructional materials. When instructional material and diagnostic development have occurred simultaneously, it has been within a limited range of educational experience needed by particular children who have specific learning deficits (Frostig et al., 1961; Frostig \& Horne, 1964, Karnes, 1969). Even though a common rationale has not guided the overall development of diagnostic tests and instructional materials, most of these devices would appear to have their place in an educational program for a child experiencing learning difficulties if a common procedure were established in analyzing both types of information. Without a common procedure the classroom teacher currently finds it difficult to determine what materials to use based on diagnostic information to decide if materials are at all complimentary to one another. The teacher discovers many theoretical positions presented for teaching children with specific learning disabilities (Cruickshank et.al., 1961; Ebersole, Kephart and Ebersole, 1968; Johnson and Mykelbust, 1967; Kephart, 1960; Peterson, 1967) and many instructional materials for remedial teaching, but no logical system for combining the theories and the materials. The purpose of this article is to propose a system for teachers to use in analyzing instructional materials as well as for modification or development of materials for use with children possessing specific learning strengths and weaknesses.

1. Dr. E. Eugene Ensminger is Associate Professor of Special Education and Coordinator of the Learning Disabilities Program at Georgia State University. $\mathrm{He}$ is former Director of the Regional Special Education Instructional Materials Center and Coordinator of the Learning Disabilities Program at the University of Kansas. 


\section{INSTRUCTIONAL MATERIALS FOR THE HANDICAPPED}

Perhaps the greatest single contribution to the instructional materials movement was the establishment of the Instructional Materials Center Network for Handicapped Children and Youth (Olshin, 1968). The Regional Special Education Instructional Materials Centers making up the IMC Network have had the effect of making materials available at the local level through the development of local IMC's.

While instructional materials are more readily available to the teacher today than they were a decade ago, the availability of materials for use with children still leaves much to be desired. In addition to availability, or where to locate materials, is the question of what materials to use for specific children. In other words, what rationale is to guide the teacher in selecting materials most appropriate for the learning characteristics of the child? It would seem that if a rationale for selection of materials were available, then the same rationale could be used for modifying materials, developing new materials, evaluating materials, and providing a diagnostic model as well.

\section{DIAGNOSTIC EVALUATION OF THE LEARNER}

The second significant contribution of the 1960's to the education of handicapped children has been the renewed emphasis upon diagnostic testing as opposed to the previous use of tests to provide classificatory information (Kirk and McCarthy, 1961). This approach has emphasized the ferreting out of specific learning characteristics of the learner with the goal of prescribing educational activities to match the particular characteristics of

FOCUS ON EXCEPTIONAL CHILDREN is published monthly except June, July, and August as a service to those concerned with mentally retarded and emotionally disturbed children. Subscriptions rates, $\$ 9.50$ per year. Copyright 1970 Love Publishing Company. All rights reserved. Reproduction in whole or part without written permission is prohibited. Printed in the United States of America. Second class postage is paid at Denver, Colorado.

$$
\begin{gathered}
\text { Executive and Editorial Offices } \\
6635 \text { East Villanova Place } \\
\text { Denver, Colorado } 80222 \\
\text { Telephone (303) } 757-2579
\end{gathered}
$$

\section{EDITOR}

Dr. Edward L. Meyen

The University of Iowa

Washington Report

Valeita J. Naegle
Stanley F. Love Publisher the child. Although each diagnostic test has been developed upon a theoretical model (e.g. Frostig, 1961; Kirk, McCarthy and Kirk, 1969; Roach and Kephart, 1966) and each emphasized certain learning experiences related to educational achievement, none of the models is allinclusive. Thus none of the models provides for adequate assessment for the entire range of learning characteristics of the child for subsequent educational programming. It should be emphasized that many of the diagnostic models have overlapping components, but they tend to look at only a narrow band of learning behavior. Thus, in order to adequately survey the learning behaviors of each individual child, many diagnostic instruments must be employed.

Many approaches to the analysis of test results have been proposed, and recommendations made regarding subsequent educational treatment. Some have followed the deficit approach in which the primary educational prescription is for purposes of increasing the efficiency of the child in the identified deficit area (Kirk and Bateman, 1962; Olson, Hahn and Herman, 1965; Kirk, 1966). This procedure provides for improving the educational deficit but does not give the teacher information on what to do for the child in other areas of instruction. The approach has generally treated the learner in a very fragmentary way, and the performance of the child in other learning areas receives less emphasis in planning the total educational program. Still other approaches have proposed that diagnostic tests should look not only at the deficits of the learner but also at his strengths (e.g., McCarthy, 1967). This technique utilizes all diagnostic information for prescribing a more complete educational program for the learning disability child but still doesn't tell the teacher what to do.

More specific procedures have been proposed which analyze each individual response made by the child as opposed to item classification deficit procedures (i.e., auditory decoding) for determining the starting point for remedial instruction. In some instances this approach to the analysis of a child's performance has utilized the subtest analysis technique in combination with classroom observation of the child's learning behavior. In the subtest analysis procedure, each subtest is reviewed and the child's response deficits are specified. Educational programming is then planned around the specific deficits identified by the analysis. When classroom observation is employed, the diagnostician can observe the child performing educational tasks and determine how the identified deficits found in subtest analysis correspond to class- 
room performance. The classroom observation approach uses the educational tasks provided by the curriculum as the diagnostic base. Subsequent educational programming is designed around the deficits the child demonstrates in a non-standardized educational setting (the classroom). This latter approach would appear to be one of the most practical techniques if a school system is fortunate to have enough educational specialists with an understanding of curricula and educational objectives as well as sufficient time for observation. Basing educational programming upon the child's response to educational tasks has the distinct characteristic of being more specific to the learning task and allowing the instructional program to teach those skills the child has not accomplished.

The task analysis proceduce (observation of child when performing educational tasks) is a valuable procedure, but most teachers have difficulty in analyzing the various components of a task. In addition, no systematic procedure for determining the adjustment of the educational program for a particular child is available from one source to guide the teacher in this endeavor. A procedure for assisting the teacher in analyzing and prescribing for a specific learning situation is the modality approach (L'Abate, 1969; Wepman, 1967). The modality procedure considers both the stimulus presented to the child and the response made by the child. This approach is an input-output model (L'Abate, 1969) which emphasizes the visual and auditory inputs and the motor and verbal outputs. By describing the complexity of the stimulus and the response, the educational task can be modified to match the level of the learner on either end of this learning paradigm.

\section{GENESIS OF THE MODALITY APPROACH}

Modality learning is based upon communication theory and has been applied to human learning through models proposed by Osgood (1957) and Wepman (1960). The educational application of these models can be found in the development of the Illinois Test of Psycholinguistic Abilities (McCarthy and Kirk, 1961). The Illinois Test of Psycholinguistic Abilities (ITPA) was first published in its experimental edition in 1961. This instrument was developed and published with the expressed intent of providing a diagnostic device that would stimulate remediation programs based on the diagnosis. Instead of classifying children, as was the practice with most earlier assessment devices, the emphasis was on identifying basic learning deficits with the goal of planning an educational program for remediation of the deficit. The 1961 experimental edition of the ITPA as well as the 1968 Revised Edition (Kirk, McCarthy and Kirk, 1969) categorized language along three dimensions. Language ability is viewed as being of two levels of organization (meaningful and non-meaningful language), three processes of assimilation (reception, association, and expression) and two channels of communication (auditoryverbal and visual-motor).

Channels of communication then refer to the manner in which a child receives sensory information and how he responds to that information. In the ITPA model, only two combinations of input-output were included. These two channels are the most common avenues of communication exchange, i.e. a child hears and then he speaks or a child sees and then he grasps, points, gestures, etc. Other combinations of input-output are possible as well as multiple input-output combinations, i.e. visual input and verbal-motor output. Wepman (1967) has referred to those channels as modalities or pathways of learning and has indicated that children are of certain learning types and thus they prefer certain input-output modalities for learning.

Current practice in many educational programs for children with learning disabilities is to prescribe remediation based on the child's strength or weakness in one of the learning channels. For example, if the child's strength is in the auditory - verbal channel the recommended approach to teaching reading is generally a phonetic-or linguistic-based approach. On the other hand, if a child has a basic strength in the visual-motor channel his visual strength is emphasized through the use of a whole word or sight word approach in teaching the child to read. As can be noted, however, the input modalities are of main consideration in the above examples rather than the output modalities. Although empirical evidence supporting such an approach to instruction is scarce, some evidence has been accumulated by L'Abate (1969) indicating support for the input-output approach as a diagnostic techinque. The most important feature of the input-output procedure for instruction is that it requires the person doing the instructing to analyze the learning task in addition to the evaluation of the child.

\section{A MODEL FOR SELECTING MATERIALS}

With the great abundance of commercially prepared instructional materials currently available for the remediation of specific learning problems of children, it is indeed a difficult task for the teacher to determine what 
materials are most appropriate for a specific disability. In addition, producers of materials often advertise specific materials as being the solution to all of a child's problems when in fact they may be appropriate only for a certain level of development through which the child has already passed. Thus the absence of a clearly defined sequence for selecting instructional materials provides for more uncertainty because the teacher is left without a system for determining what instructional materials either precede, compliment, or follow any other instructional material. In addition, the teacher is left without a rationale for modification or development of materials when they are inappropriate for a child's level of functioning. This dilemma has provided for discontinuity in the educational programs for children with learning disabilities, and the absence of a comprehensible programming model for the teacher has lead to the perpetuation of a fractionated educational program.

\section{LEARNING STAGES}

The Instructional Model presented in Figure 1 suggests a conceptual framework for evaluating the instructional experiences necessary for children to ultimately perform successfully in academic areas. This model suggests that two basic components must guide the teacher in planning a sequential program. First, the development stages of learning must be considered, with early learning being primarily of a motor nature while later learning is primarily symbolic. The four learning areas presented in this model are certainly not discrete since each level can be broken down into smaller stages. Each stage of development is also dependent upon experiences at a previous level or levels.

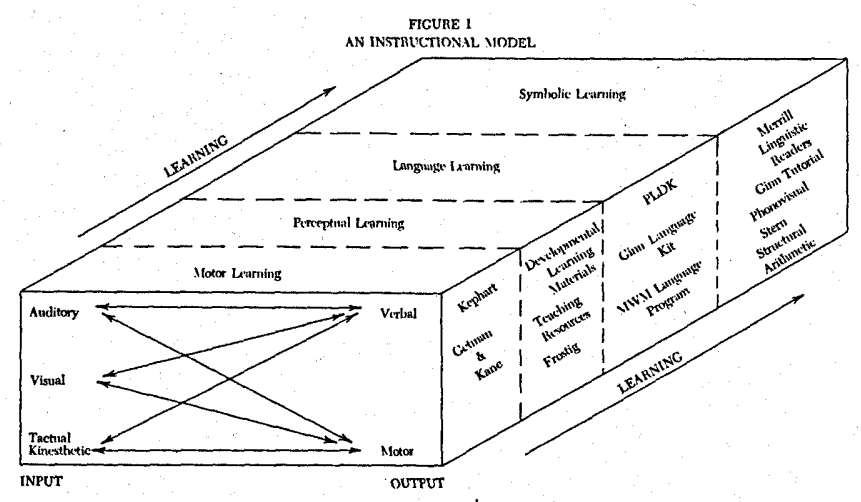

The Motor Learning stage in the suggested instructional model incorporates the gross-motor stage, the motor- perceptual stage, and the perceptual-motor stage described by Ebersole, Kephart and Ebersole (1968). Initial experiences of the child involve motor learning. Roach and Kephart's (1966) perceptual motor theory has emphasized the importance of early motor learning for the subsequent development of more complex learning. Basic to this theory are the early interactions of the child with his environment. These early interactions are largely of a gross-motor nature. Through motor exploration the child comes in contact with objects within his environment, and after repeated contacts he begins to gather basic perceptual information. This basic perceptual information is gathered through touching, handling and manipulating of objects in the child's immediate surroundings, and gross-motor responses provide perceptual information. The child progresses from the gross-motor stage to the motor-perceptual stage. As the child begins to depend on perceptual information for motor responding, the child progresses to the perceptualmotor stage. These early motor learnings will eventually allow the child to gain information perceptually without extensive motor experiences.

In addition to the perceptual information being associated with the tactual and kinesthetic experiences during the motor learning stage, the child establishes a common reference point for later interpretation of perceptual information. Through motor contact with objects in the environment the child establishes an internal awareness of his own body with respect to environmental information. This early information is accumulated through repeated motor movements and the tactual-kinesthetic stimuli received (feedback) through motoric exploration. The information input to the child in the early stages is essentially tactual and kinesthetic and the output is primarily of a gross motor nature. As perceptual information becomes meaningful, the motor responses of the child are controlled by his visual and auditory perceptions. When perceptual information leads to the same information as that received from motor exploration, the child has achieved the "perceptual-motor match" (Ebersole, Kephart and Ebersole, 1968).

Children with learning disabilities at the Motor Learning Stage may still need to gain basic perceptual information by additional motor exploration. Programs for training gross-motor and perceptual-motor skills have been published by Kephart (1960) in his book The Slow Learner in the Classnoom and by Getman and Kane (1964, 1968). These programs emphasize the importance of the child gaining control of his own body in mov- 
ing within his environment. As he gains control of his own body movements the child establishes a relationship to other objects with respect to orientation of his own body as well as time and space. Unless the child has achieved these basic learnings he will experience difficulties in tasks that are primarily of a perceptual nature.

The basic rudiments of perceptual learning occur in combination with motor learning. In many instances children first demonstrate their disabilities in school when a response must be made to perceptual information. Paper and pencil activities may be totally inappropriate, and the child may need to begin with activities involving large muscle action and real or replicas of objects, i.e. stacking large blocks (6" $\times 6$ " $\left.\times 10^{\prime \prime}\right)$ to match another stack of large blocks provided as a model. As the child becomes proficient at this task the model stack could be associated with a line drawing of the stack of blocks and the child would then stack the blocks to match the model stack and the line drawing. The next phase would be to remove the model stack of blocks so that the child could stack the blocks from the line drawing only. This procedure allows for Motor Learning while permitting the teacher to allow the response to remain constant as he modifies sequentially the complexity of the visual information. While the child is able to be successful at the motor level, the instructional program can take advantage of this strength and provide training in the visual perceptual area.

Chalkboard activities (Kephart, 1969) also permit the child to use large muscle activities for responding by tracing, copying or following stencils. Activities of this type refine the motor coordination skills while at the same time the perceptual skills are being sharpened.

The Perceptual Stage of the instructional model then continues from the simple to the complex with many of the more refined perceptual activities occurring at the child's desk. Perceptual training programs have been developed by Strauss and Lehtenin (1947), Cruickshank et al. (1961) and Peterson (1967) for using stencils, pegboards, cubes and parquetry blocks as the instructional media. An entire series of stencils, cubes and cube patterns, parquetry blocks and parquetry patterns have been produced and published by Developmental Learning Materials (1967). Materials for instruction at this stage are also available from Teaching Resources (Cheves, 1967; Dubnoff et.al., 1968; Hatton et.al., 1967). These provide perceptual training activities requiring finer perceptual skills as well as finer motor coordination skills while still permitting the child to manipulate objects for improving his perceptual skills.

When the child is successful at this level of perceptual learning, paper and pencil activities can be initiated using stencils of forms, tracing patterns, copying forms or reproducing simple forms from memory. As perceptualmotor skills are refined, the child can be presented materials like those developed by Frostig and Horne (1964). These materials provide training in eye-hand coordination, form constancy, position in space, figureground, and spatial relationships. When the child experiences difficulties with any of these tasks, the teacher can replicate these activities so that motor learning can occur. In other words the task can be made more concrete so that the child can motorically experience the activity by walking around the pattern traced on the floor or chalkboard.

Also occurring at the Perceptual Learning Stage is the acquisition of auditory skills. Auditory perceptual learning has received far too little attention in the form of commercially prepared materials. Auditory skills are of tremendous value when symbolic learning is introduced into an educational program. Reading is primarily the operation of transforming visual symbols into auditory symbols. The task of recognizing and discriminating sounds should be introduced into the educational program in a very consistent and systematic way in the child's early school experiences, if not before. Materials for auditory perceptual learning can be acquired from the Canadian Association for Children with Learning Disabilities in Toronto. The Knowledge Aids Division of the Radiant Corporation has recently published Follow through with Sounds that presents indoor and outdoor sounds. These sounds are on tape or records and pictures of indoor-outdoor scenes accompany the auditory materials. In almost all instances auditory skills can be simultaneously developed while training visual auditory perceptual skills. However, the educational program should provide training that emphasizes the acquisition of auditory perceptual skills. Many of the language development programs described below also provide experiences for auditory perceptual learning.

The Language Learning level of the instructional model suggests experiences that build upon motor learning and perceptual learning as well as to occur concurrently with the development of motor and perceptual skills. It could be argued that all learning, including the motor skills, is basically the acquisition of a language system. In all instances the child is learning to communicate with his environment, thus all learning is langu- 
age learning only at different levels of stimulus and response complexity. Language development programs have essentially emphasized the production of Verbal Language. These programs stimulate language development through developing vocabulary, describing items, following directions, memory of visual and auditory sequences, classification of objects and words, listening, and productive thinking. Language learning is crucial to later success in symbolic learning and to the entire thinking process. It has been suggested that verbal learning controls behavior (Luria, 1961) and it has been demonstrated that children verbalizing while solving arithmetic problems improve their performance (Lovitt and Curtiss, 1968). These findings have implications for motor and perceptual learning, and suggest that they would be more efficient if the child described verbally what he does.

Commercial materials available for stimulating language development include the Peabody Language Development Programs (Dunn and Smith, 1965, 1966, 1967; Dunn, Horton and Smith, 1968). The Ginn Language Kit $A$ (1965) and the MWM Program for the Remediation of Language Learning Disabilities, 1970. The Peabody Language Development Programs come in four different kits encompassing language development activities from pre-school through about third grade. Each kit treats the development of language from a global point of view and enough daily lessons are included in each kit to provide an academic year program. The MWM Program is a sequence of language activities based on the Illinois Test of Psycholinguistic Abilities, Revised Edition. The specific purpose of this program is to provide remediation activities for deficits shown on the ITPA although the authors emphasize that it is a development program as well as remedial program. Other language programs also have been developed using the ITPA as the model for developing activities (Karnes, 1969).

The fourth stage of the suggested instructional model is concerned with Symbolic Learning. Basic to successful symbolic learning are the learnings which occur at the motor, perceptual, and language levels described above. The symbolic learnings encompass those activities that are commonly thought of as academic. At this level, language symbols are acquired in the areas of reading, writing, spelling, and arithmetic. Many different reading programs are available and each is dependent upon the particular modality strengths of the child. The learning characteristics of the child must be considered when selecting a particular reading program. Reading programs that would appear to have merit in teaching the child with a symbolic learning disability are: The Ginn Tutorial reading program (Ellson et. al., 1968) the Sullivan reading program (Sullivan \& Buchanan, 1963), the Merrill Linguistic Readers. (Fries et.al., 1966), the Phono-Visual Method (Schoolfield \& Timberlake, 1967), and the Experience Approach to Teaching Reading (Allen \& Allen, 1966). An exemplary arithmetic program would be the Structural Arithmetic Program (Stern et.al., 1952) which comes in three kits along with cubes, counting frames, and other concrete perceptual aids. The Science Research Associates (GCMP) arithmetic program (Thoburn \& McCraith, 1962) with its accompanying drill tapes and overhead transparencies is also useful. The particular program used for a child with a learning disability should always be guided by the input-output dimensions described below.

\section{INPUT-OUTPUT SYSTEMS}

The second component of the suggested instructional model is the input-output systems of receiving and expressing information at any one of the developmental stages. The arrows on each of the various input-output combinations represent not only the fact that information is received and responded to but that feedback is received from the response which confirms or negates the accuracy of the information received. The input-output dimensions of the instructional model presented in Figure 1 highlights the importance of analyzing instructional materials with regard to the manner in which stimuli are presented and the responses expected from the child. Any combination of input and output is possible as well as any combination of inputs and outputs. Through this approach to analysis of instructional materials, the inputoutput dimensions of materials can be matched to the input-output dimensions of the learner. Although the ideal is for all modalities to be efficient in the process of learning, some children are found to have difficulties in processing information adequately through certain modalities. For these children, other sense modalities and response modalities may need to be used for instruction so their educational experiences can be successfully rewarding.

The implication of the input-output technique is that when children are having difficulties in responding to auditory stimuli it may be necessary to provide visual or tactual information to assist the child in making a response. On the other hand the child may be able to un- 
derstand the stimuli but is unable to make the response expected of him. In this case, the type of response the child is to make may need to be altered. Using the example above, the child may be able to understand the auditory stimuli but unable to make the expected verbal response. By permitting a multiple-choice verbal response provided by the teacher, the child might be able to successfully complete the task. On the other hand, the child might be allowed to make a motor response by pointing to a picture which demonstrates that he understands the auditory stimulus. The child's successful responding with a motor response may not be the desired one but it does indicate that he understands. The teaching tasks then must be directed toward sequential training the verbal response system. The input-output technique then isolates the learning difficulty and allows for specific programming based on either an input or output dysfunction rather than the combination which can lead to confusion for the teacher and the child.

A final consideration to be made regarding the inputoutput component of the instructional model is the complexity of the input or output. Examples of types of input and output are presented in Table 1. These are not considered to be inclusive but are presented here as examples of how the stimulus or response can be increased

TABLE 1

\section{AN EXAMPLE OF INPUT-OUTPUT HIERARCHIES}

Auditory

1. Gross Sounds

2. Speech Sounds

3. Single Words

4. Multiple Words

5. Single Directions

6. Multiple Directions

Verbal

1. Yes or No

2. Labeling

3. Phrase

4. Sentence

5. Sequence of Labels

6. Sequence of Ideas

\section{INPUT}

Visual

1. Real Object

2. Replica or Model

3. Photograph

4. Line drawing

5. Abstract picture

6. Picture (missing parts)

7. Symbols

\section{OUTPUT}

\section{Motor}

1. Walk toward

2. Point

3. Pantomime

4. Trace

5. Copy

6. Match objects

7. Multiple Choice (2 or 3 item)

8. Complete

9. Order (series of letters)

10. Write from recall

in complexity through the various modalities. To demonstrate how the stimulus complexity can be utilized for programming, assume the child has been given three directions to follow and he is to respond by performing the

tasks specified in the directions, i.e. pick up a book, close the door, and then stand on a chair. The child can do each of these tasks individually but he cannot remember all three when given as a multiple direction. The auditory input is too complex and thus the number of auditory directions will need to be reduced. The teaching task now demands the sequential development of a program to improve the number of auditory directions that can be given with subsequent successful execution by the child. The other input and output modalities can be modified in a similar manner. The input-output component of the instructional model adds a dimension of flexibility to any instructional material by providing a framework on which to modify the material for a child who is unable to learn through standard procedures.

In summary, the proposed model is not presented as a panacea for all instructional problems but it is presented as a model that can provide a frame of reference for making instructional decisions. The current state of the art in instructional materials continues to place a heavy demand upon the teacher to make adjustments in the educational program. The instructional model presented here demands that the teacher assume the responsibility for the child's failure to accomplish a task as a result of not adjusting the input-output functions of the instructional materials to match the input-output functions of the child. This paper has not considered a most crucial aspect of any learning experience-reinforcement. A systematic reinforcement procedure must always be employed to insure maximum learning in any instructional program.

Finally, it is hoped that material developers and publishers will ultimately provide instructional materials with suggested alternatives for adapting them to children having input or output deficits. The clinical teacher will always be necessary, but systematically developed instructional programs will be the only way of reducing instructional variability for the handicapped child.

\section{REFERENCES}

Allen, R. V. \& Allen C. Language experiences in reading. Chicago: Encyclopedia Britannica Press, 1966.

Cheves, R. Visual-motor perception teaching materials. Boston: Teaching Resources, 1967.

Clymer, T., Christenson, B. M. \& Russell, D. H. Building pre-reading skills; Kit A, language. Boston: Ginn and Company, 1965.

Cruickshank, W. M., Bentzen, F. A. Ratzeburg, F. H., \& Tannhauser, M. T., A teaching method for brain-injur- 
ed and hyperactive children. Syracuse, New York: Syracuse University Press, 1961.

Dubnoff, B., Chambers, I., \& Schaefer, F. Dubnoff school programs: Experimental perceptual-motor exercises. Boston: Teaching Resources, 1968.

Ebersole, M., Kephart, N. C., \& Ebersole, J. B. Steps to achievement for the slow learner. Columbus, Ohio: Charles E. Merrill Publishing Company, 1968.

Ellson, D. G., Barber, L. W., Harris, P. L., \& Adams, R. B. Ginn tutorial: A tutorial system. Boston: Ginn and Company, 1968.

Fries, C. C., Wilson, R. G., \& Rudolph, M. K. Merrill linguistic readers. Columbus, Ohio: Charles E. Merrill Publishing Company, 1966.

Frostig, M. \& Horne, D. The Frostig program for the development of visual perception: Teachers guide. Chicago: Follett Publishing Company, 1964.

Frostig, M., Lefever, D. W. \& Whittlesey, I. R. Developmental test of visual perception. Palo Alto, California: Consulting Psychologists Press, 1961.

Getman, G. N. \& Kane, E. R. Developing learning readiness. New York: McGraw-Hill Book Company, 1968.

Getman, G. N. \& Kane, E. R. The physiology of readiness: An action program for the development of perception in children. Minneapolis, Minn.: Programs to Accelerate School Success, 1964.

Hatton, D. A., Pizzat, F. J. \& Pelkowski, J. M., Perceptual-motor teaching materials, Erie program 1. Boston: Teaching Resources, 1967.

Johnson, D. J. and Myklebust, H. R. Learning disabilities: Educational principles and practices. New York: Grune \& Stratton, 1967.

Karnes, M. B. Helping young children develop language skills: A book of activities. Washington. D. C.: The Council for Exceptional Children, 1969.

Kephart, N. C. The slow-learner in the classroom. Columbus, Ohio: Charles E. Merrill Publishing Company, 1968.

Kirk, S. A. The diagnosis and remediation of psycholinguistic disabilities, Urbana, Illinois: Institute for Research on Exceptional Children, University of Illinois, 1966.

Kirk, S. A. and Bateman, B. "Diagnosis and remediation of learning disabilities.” Exceptional Children, 1962, 29, 73-78.

Kirk, S. A. and McCarthy, J. J. “The Illinois Test of Psycholinguistic Abilities an approach to differential diagnosis." American Journal of Mental Deficiency, 1961, 66, 399-412.
Kirk, S. A., McCarthy, J. J., and Kirk, W. D. Illinois Test of Psycholinguistic Abilities, revised edition. Urbana, Illinois: University of Illinois Press, 1968.

L'Abate, L. "An input-output approach to psychodiagnosis of children, World Journal of Psychosynthesis, 1969, 1, 68-73.

Lovitt, T. C. \& Curtiss, K. A. "Effects of manipulating an antecedent event on mathematics response rate." Journal of Applied Behavior Analysis, 1968, 1, 329333.

Luria, A. R. The role of speech in the regulation of normal and abnormal behavior. New York: Pergamon Press, 1961.

McCarthy, J. J. and Kirk, S. A. Illinois Test of Psycholinguistic Abilities, experiment edition. Urbana: Institute for Research on Exceptional Children, University of Illinois, 1961.

McCarthy, J. M. Psychoeducational diagnosis - a derivative of classroom behavior. Unpublished manuscript, Community Consolidated School District 54, Hoffman Estates, Illinois, 1967.

Minskoff, E. H., Wiseman, D. E., Minskoff, J. G. The $M W M$ program for the remediation of language learning disabilities, Chicago: Follett Educational Publishers, in press.

Olshin, G. M. Special education instructional materials center program. Exceptional Children, 1968, 34, 515519.

Olson, J. L., Hahn, H. R., and Herman, A. L. "Psycholinguistic curriculum." Mental Retardation, 1965, 3, 14-19.

Osgood, C. E. Motivational dynamics of language behavior. Nebraska Symposium on Motivation. Lincoln: University of Nebraska Press, 1967.

Peterson, W. "Children with specific learning disabilities." In N. G. Haring and R. L. Schiefelbusch, (Eds.), Methods in Special Education. New York: McGraw-Hill Book Company, 1967, pp. 159-208.

Schoolfield, L. D. and Timberlake, J. B. The phonovisual method. Washington, D. C.: Phonovisual Products, 1967.

Sounds and Patterns. Chicago: Knowledge Aids Division, Radiant Corporation, 1968.

Stern, C., Stern, M. B. \& Gould, T. S. Structural arithmetic. New York: Houghton Mifflin Company, 1952.

Strauss, A. A. and Lehtinen, L. E. Psychopathology and education of the brain-injured child. New York: Grune \& Stratton, 1947.

Sullivan, M. W. and Buchanan, C. D. Programmed 
reading. New York: McGraw-Hill Book Company, 1963.

Thoburn, R. and McCraith, L. Greater Cleveland mathematics program. Chicago: Science Research Associates, Inc., 1962.

Wepman, J. M. “The perceptual basis for learning. "In E. C. Frierson \& W. B. Barbe, Educating children with learning disabilities. New York: Appleton-CenturyCrofts, 1967.

Wepman, J. M., Jones, L. V., Bock, R. D., and Pelt, D. V. "Studies in aphasia: Background and theoretical formulations." Journal of Speech and Hearing Disorders, 1960, 25, 323-332.

Woodcock, R. W. Peabody rebus reading program. Circle Pines, Minn.: American Guidance Service, 1967.

\section{COMMUNITY EXPECTATIONS OF THE MENTALLY RETARDED}

\section{Cary L. Reichard, Ed. D. ${ }^{1}$}

Adequate vocational adjustment for the retarded is in part determined by a community's acceptance of them as potential contributors to society. Attitudes reflecting "what pupils cannot do" could be detrimental in terms of job acquisition and success. Therefore, it would be to the advantage of the retarded if communities were made aware of the things the retarded "can do" as well as their limitations.

Preconceived expectations on the part of teachers, whether positive or negative, have been found to directly affect a student's achievement (Rosenthal, 1966). If this information is correct, we can assume that the expectations of an employer in regard to a potential employee, would to some extent affect job success or failure. Therefore the efforts of a good teacher, with effective teaching methods and a sound curriculum based on com-

1. Cary L. Reichard is a member of the faculty of the Department of Special Education, School of Education, University of Florida. munity adjustment, might well break down due to a community's inappropriate expectations of the retarded. The point is clear. Special educators cannot afford the costs of programming for the retarded when the outcome may still result in social failure. If negative attitudes toward the retarded exist in communities-and research generally supports this assumption-measures must be taken to alleviate these attitudes.

There is reason to believe that we as special educators are unconsciously responsible for some of the negative attitudes existing in the community. One hundred master-level students majoring in special education were asked to list three educational characteristics of the retarded, (Reichard, 1969). The following represents the characteristics most frequently listed:

(1) Low intelligence

(2) Minimal academic achievement

(3) Behavior disorders

(4) Lack of motivation

(5) Short attention spans

(6) Difficulty with abstract concepts

(7) Sequencing problems

(8) Perseveration

A decision as to whether or not this list of characteristics is completely, or only partly, descriptive of the mentally retarded is of little importance in this paper. What is important is that all but fifteen of the three hundred responses had negative overtones, citing inabilities rather than abilities. It is important to know a child's limitations, but it is of equal importance to understand and report the things he can do. For example, it is believed that approximately $50 \%$ of the cerebral palsied fall within the intelligence range of mental retardation. However, this same statement having negative overtones could well be said positively by stating that approximately 50 of the cerebral palsied fell within the range of normalcy.

Determining and recording a pupil's limitations is an integral part of program planning for the retarded child. But the community must be made aware of the positive aspects of the retarded. (1) They can become gainfully employed. (2) They can become self sufficient. (3) They can participate in community social functions. (4) They can learn to read, write, and perform arithmetic. (5) They can learn to effectively communicate and interact with their social peers. As special educators let us keep in mind and accentuate the positive aspects of 
the retarded. We can and must develop a respectful community image for the retarded.

\section{REFERENCES}

Reichard, Cary L. "Professional Attitudes of the Retarded," (Unpublished) October, 1969.

Rosenthal, Robert, and Jacobson, L. "Teachers' Expectancies: Determinants of Pupils' I.Q. Gains." Psychological Reports. 1966, Vol. 19, 115-118.

\section{WASHINGTON} REPORT

Thousands of additional teachers and specialized personnel must be trained if special education services are to be provided for more than three million handicapped children not enrolled in special education programs.

Public Law 85-296, as amended by Title III, Section 301 of Public Law 88-164 provides grants for the training of such specialists in the education of the handicapped. Public Laws 89-105 and 90-170 further expanded this program and extended it through Fiscal Year 1970, providing $\$ 37,500,000$ for Fiscal Year 1969 and $\$ 55,000$,000 for Fiscal Year 1970.

Of these funds a portion has been allocated to support the development of special projects concerned with training of special educators. The special project is seen as an opportunity to provide greater flexibility in personnel preparation through better training programs. The special project award program is designed to encourage the conceptualization and implementation on an experimental basis, of approaches to training which are new or significant modifications of existing programs. The program will encourage innovation in solving major training problems. It will not provide for minor changes in established programs.

The following are examples of types of special projects which are fundable under the special projects award program:

1. Conferences to formulate new concepts in preparing special education personnel.

2. Programs to train clinical supervisors, master teachers, practicum supervisors, evaluation specialists and other personnel.

3. Utilization of manpower previously untapped for participation in special education programs (e.g., training programs for inactive teachers, liberal arts graduates and retired military personnel).
4. Conceptualization of new programs to prepare educators at the doctoral or post master's level.

The above are for illustration only and do not represent the entire range of possible special projects which would be acceptable to the Bureau of Education of the Handicapped.

No deadlines have as yet been established for special projects. Applicants, therefore, may submit proposals at anytime throughout Fiscal Year 1970. For additional information write: Special Projects, Division of Training Programs, Bureau of Education for the Handicapped, United States Office of Education, 7th and D Streets, S. W., Washington, D. C. 20202.

\section{RESOURCE MATERIALS}

By Reuben Altman and Linda Smith

\section{BELL AND HOWELL}

The Bell and Howell Language Master Audio-Visual Instructional System has been developed to facilitate language arts instruction including reading, oral communication, grammer skills, and foreign language. Basic to the system is the Language Master machine which utilizes dual-track programmed cards containing magnetic strips on which lesson material has been prerecorded. The second track allows the child to record his response or repetition of the programmed material for evaluative purposes. The available programs ranging in grade level from pre-school through college include the Vocabulary Builder Program, the Language Stimulation Program, the Phonics Program and a Talking Dictionary Series. In addition to the prepared card sets and programs, blank cards are available for use in tailoring materials to a child's specialized needs.

Bell and Howell has recently introduced a language rehabilitation program for aphasics. The Aphasia/ Language Rehabilitation Program provides individualized auditory and visual recognition drill for aphasics and others suffering from speech impairments. The program includes diagnostic tests that indicate the extent of the child's language disability and determine the point within the program at which therapy should commence.

1. Reuben Altman is Consultant and Linda Smith is Curriculum Specialist, Special Education Instructional Materials Center, University of Texas. 
The Language Master sells for $\$ 250.00$ and individual programs containing 200 cards each are approximately $\$ 35.00$. The complete Aphasia/Language Rehabilitation Program is $\$ 89.00$. For illustrated brochures and additional information write: Bell and Howell Company; Audio-Visual Products Division; 7100 McCormick Road; Chicago, Illinois 60645.

\section{EXECUTONE}

Occasionally during the academic year some children will be confined to their homes consequent to injuries, the onset of contagious diseases, or other disabilities such as orthopedic or cardiac conditions. The Executone School-to-Home Telephone System provides an opportunity for these homebound or hospitalized children to continue their education with a minimum of disruption. Both home and school communication units are used in conjunction with standard private telephone lines. The home station includes a talk switch and volume control enabling the student to participate in actual classroom activities. This direct communication technique is of particular value in overcoming the detrimental social and psychological concomitants of isolation and seperation from peers. School-to-Home Service is provided on. a rental basis by the Bell Telephone System and independent telephone companies nationally. Executone offers a free informative handbook entitled "How to Teach Shut-In Students by Telephone." For further information call your local telephone company, or write to: Special Education Division; Executone, Inc.; 47-37 Austell Place; Long Island City, New York 11101.

\section{CHILD SAFETY EDUCATION ASSOCIATION}

The Child Safety Education Association is a non-profit corporation dedicated to the promotion and perpetuation of child safety training in the elementary grades. Materials for a total safety program include an introductory Parent-Teacher Letter recruiting the cooperation of each parent in the implementation of the program. Also available are 18 aluminum safety signs as well as student coloring books encouraging the recognition, drawing and reading of common safety warnings. The $A B C$ 's of Safe$t y$ depicts in full color and story form various safety reminders involving electric shock, fire, knives, poison, pedestrian hazards, etc. Successful completion of the program culminates in the child's receipt of an Award of Merit suitable for framing. A teacher's guide outlines the Child Safety Training Aid Program and details its several components. Sample materials may be request- ed from: Child Safety Education Association; 941 Third Avenue North; P.O. Box 1674; Naples, Florida 33940.

\section{NOBLE AND NOBLE PUBLISHERS, INC.}

Noble and Noble produces Try: Experiences for Young Children, a readiness program designed specifically to help develop visual-motor skills and oral language facility in children from ages 4-7. It is presented in the form of three tasks, each including one activity book, one set of three-dimensional manipulative materials, and one Teacher's Guide. Each perforated page in the child's Activity Book consists of a Visual-Perceptual Experience accompanied by a related Expressive Experience providing opportunities in discrimination ranging from patterns, shapes and sizes to alphabet letters and punctuation. Other Try activities attempt to promote the development of communication skills, a positive self-image, and imaginative expression. The entire program is constructed to permit children to work independently and progress at their own rate.

Noble and Noble also publishes the five-book Urban Primary Reading Series, intended for use in grades 1 and 2 with the culturally deprived, the emotionally disturbed, and the mentally retarded. These materials are particularly useful in multiethnic communities as a function of their silhouetted illustrations satisfying the need for integrated texts. A brochure and order form may be obtained from: Noble and Noble Publishers, Inc.; 750 Third Avenue; New York, New York 10017.

\section{ISSUES}

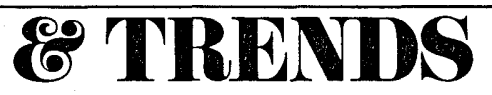

Ensminger, in the feature article of this issue, discusses a model for developing instructional materials. The model employs many techniques inherent in systems analysis. Considerable attention is currently being given to systems analysis in the broader field of special education. A teacher's initial reaction to the systems approach may be one of skepticism. She may feel that writers of such articles are merely fragmenting problems and procedures without making them more meaningful. Hopefully premature judgement will not prevail, as authors apply this approach to designing models applicable to instruction for exceptional children. The outcome might well be refreshing in terms of conceptualizing new ways of coping with the instructional problems we encounter. 


\section{INDEX • VOLUME I}

Author Index

Altman, Reuben (September through February)

Ayre, Elizabeth W. (January, 1970)

Boekel, Norma (September, 1969)

Britton, Alexander L. (November, 1969)

Brown, Louis F. (May, 1969)

Carter, Phyllis (April, 1969)

Cross, Kenneth (January, 1970)

Dickie, R. F. (December, 1969)

Ensminger, E. Eugene (February, 1970)

Fangman, Thomas J. (October, 1969)

Farr, James R. (October, 1969)

Goldstein, Herbert (April, 1969)

Gozali, Joav (September, 1969)

Greenstein, Melvin (October, 1969)

Grosenick, Judith K. (October, 1969)

Hodge, Wallace (December, 1969)

Lazar, Alfred L. (December, 1969)

McNeil, Don C. (November, 1969)

Meyen, Edward L. (March \& May, 1969, January, 1970)

Pratt, Eugene C. (October, 1969)

Reed, Elizabeth W. (January, 1970)

Reed, Sheldon C. (January, 1970)

Reichard, Cary L. (February, 1970)

Retish, Paul M. (November, 1969 \& January, 1970)

Robbins, Michael J. (April, 1969)

Smith, Linda (September through February)

Swan, Robert J. (November, 1969)

\section{Subject Index of Articles}

Preparation of life experience units for teaching the educable mentally retarded (March, 1969)

Construction of a social learning curriculum (April, 1969)

Strategy for the preparation of clinical educators (April, 1969)

Curriculum development for exceptional children: a focus on evaluation (May, 1969)
Evaluation: some informal techniques for classroom use (May, 1969)

The expectancy phenomena: implication for edu-

- cating the mentally retarded (September, 1969)

The influence of teacher expectations on the performance of the educable mentally retarded: a teacher's point of view (September, 1969)

Vocational training for the mentally retarded in a metropolitan setting (October, 1969)

A work-study program for rural mentally handicapped youth (October, 1969)

Experimental program in the undergraduate preparation of teachers of the emotionally disturbed (October, 1969)

Developing instructional materials for emotionally disturbed children (November, 1969)

Freedom of speech-even for the mentally retarded (November, 1969)

Interdisciplinary clinical practice: a training model (November, 1969)

The SOME system approach: a paradigm for educational instruction and remediation by the special class teacher (December, 1969)

A new training model for teachers of the mentally retarded (December, 1969)

Sex education for the mentally retarded: implications for programming and teacher training (January, 1970)

Who are the parents of the retarded children? (January, 1970)

Computer-assisted planning for special educators (January, 1970)

A proposed model for selecting, modifying, or developing instructional materials for handicapped children (February, 1970)

Community expectations of the mentally retarded (February, 1970)

Resource materials (monthly)

Issues and trends (monthly)

Washington report (monthly) 